\title{
Erratum
}

\section{An Inverse Electron-Demand Diels-Alder-Based Total Synthesis of Urolithin M7}

Ian R. Pottie, Penchal Reddy Nandaluru, Graham J. Bodwell* Synlett 2011, 2245.

The advance online publication (e-First) version of this article contained three errors:

1. In the caption of Scheme 1 the "chromone-fused diene 6" had erroneously been given as "chromone-fused diene 8".

2. In the sentence where the synthesis of compound $\mathbf{1 4}$ is mentioned, reference to Scheme 3 instead of Scheme 4 was given.

3. At the end of the last sentence before the summary reference $4 \mathrm{~d}$ was cited, but the correct reference for the mentioned isolation paper is reference 5 .

All errors have been corrected for both the current online version and the print publication. We apologize for these mistakes. 